\title{
O DESEMPENHO DE CICLISTAS E A IDADE CRONOLÓGICA EM CAMPEONATOS BRASILEIROS JUNIOR, JUVENIL E INFANTO JUVENIL
}

\author{
Performance of cyclists and chronological age in campionshipin brazilian junior, youth and children juvenile
}

\author{
JULIANA STANGHERLIN - Universidade Federal do Paraná
}

\begin{abstract}
Resumo: No presente estudo propõe verificar a freqüência da idade cronológica e o desempenho de ciclistas em campeonatos brasileiros nas categorias de iniciação, entre os anos de 2003 e 2009. Um total de 221 atletas, foram divididos em três categorias, duas provas e sexo. Posteriormente foram subdivididos em duas categorias: primeiro e segundo semestre, conforme data de nascimento. Para a análise estatística foi aplicados testes não-paramétricos binomial com "test proportion" estabelecido em 0,50 e p $\leq 0,05$. Os resultados observados não apresentaram diferenças significativas entre categorias, sexo ou prova. Essa disparidade ficou mais evidente nas categorias de base/iniciação, pois quando observada a categoria principal/profissional perde-se o referencial da linha de corte para a faixa etária. Conclui-se que há predomínio de atletas campeões nascidos no primeiro semestre, e assim como em outros esportes, os critérios adotados para a seleção e detecção de talentos é precária e subjetiva, pois avalia somente a idade maturacional, podendo excluir potenciais atletas.
\end{abstract}

Palavras-chave: idade cronológica, desempenho de talentos, ciclismo.

Abstract: This study aims to investigate the frequency of chronological age and performance of cyclists in national championships in the categories of initiation, between the years 2003 and 2009. A total of 221 athletes were divided into three categories, two races and sex. Later they were divided into two categories: first and second semester, as date of birth. For the statistical analysis was applied non-parametric tests binomial with "test proportion" set at 0.50 and $p \leq 0.05$. The observed results showed no significant differences between categories, sex or race. This disparity was most evident in the youth / initiation, when viewed as the main category / professional lose the reference of the cut line for the age group. We conclude that there is a predominance of champion athletes born in the first half, as well as in other sports, the criteria adopted for selection and detection of talents is precarious and subjective, because it evaluates only the age of maturity, but may exclude potential athletes.

Keywords: chronological age, performance of talent, cycling.

Aceito em: 25/02/2011 - Revista de Educação Física 2012 Abr - 154:18-20. Rio de Janeiro - Brasil

\section{INTRODUÇÃO}

O desempenho e a detecção de talentos de jovens atletas têm sido amplamente estudado e discutido em diferentes modalidades. A adolescência é marcada por várias mudanças no corpo, indicando diferentes graus de maturidade biológica entre indivídu(1). Estudos realizados $^{(2)}$ com ginastas, nadadores, futebolistas e tenistas, sugerem que há uma seleção natural específica por esporte relacionada à maturação sexual precoce e tardia, de forma que as adaptações induzidas pelo treinamento pouco interferiam no desenvolvimento e crescimento de jovens jogadores. Existem várias técnicas para estimar o nível maturacional, entre elas a maturação dental, a maturação somática e a maturação sexual|(3). Vários autores $^{(1,4,5)}$ adotam a idade esquelética para identificar 0 padrão maturacional de jovens esportistas.

Divergências surgem em todos os esportes devido à exclusão de atletas que ainda não atingiram a maturação. No futebol, o imediatismo e à pressão pela descoberta de novos talentos, faz com que a avaliação inicial possibilite grandes equívocos ${ }^{(6)}$, pois nem sempre aqueles que apresentam determinados requisitos nas categorias infantil (Sub-15) e juvenil (Sub 17) são aque- les que irão despontar em categorias superiores e até mesmo na categoria profissional. Em estudo recente( ${ }^{(6)}$, constatou-se no esporte competitivo que muitas vezes indivíduos nascidos no início do ano competitivo predominam numericamente sobre aqueles nascidos no final do ano competitivo, tornando-se mais evidente nas categorias de base. A diferença de idade entre indivíduos de um mesmo grupo etário ou ano de nascimento é chamada de idade relativa e sua conseqüência é chamada de Efeito da Idade Relativa - EIR(7).

O objetivo desse estudo é verificar se há relação com resultados de Campeonatos Brasileiro de Ciclismo de Estrada e Contra-relógio com o efeito da idade cronológica nas categorias Junior, Juvenil e Infanto Juvenil, entre 13 a 18 anos, do sexo feminino e masculino.

A amostra foi composta por 221 atletas entre 13 a 18 anos, integrantes das categorias junior, juvenil e infanto juvenil, do sexo feminino e masculino, das provas de estrada e contra-relógio, entre os anos de 2003 a 2009 (Tabela 1), que obtiveram as três primeiras colocações em Campeonatos Brasileiros. Foram coletadas as datas de nascimento através do site da Confederação Brasileira de Ciclismo (CBC). 
TABELA 1: Número de sujeitos estudados participantes de campeonatos

\begin{tabular}{|c|c|c|c|}
\hline Faixa Etária/Categoria & Masculino & Feminino & Total \\
\hline 18-17 anos - Junior & 42 & 33 & 75 \\
\hline 16-15 anos - Juvenil & 42 & 33 & 75 \\
\hline $\begin{array}{c}\text { 14-13 anos - Infanto } \\
\text { Juvenil }\end{array}$ & 40 & 31 & 71 \\
\hline Total & 124 & 97 & 221 \\
\hline
\end{tabular}

Identificadas a data de nascimento, os atletas foram distribuídos em duas categorias: primeiro semestre (nascidos entre $1^{\circ}$. de janeiro a 30 de junho) e segundo semestre (nascidos entre $1^{\circ}$. de julho a 31 de dezembro). A análise estatística foi aplicada no software SPSS 18.0 para teste não-paramétricos binomial com "test proportion" estabelecido em 0,50 com $p \leq 0,05$.

\section{RESULTADOS}

O resultado encontrado na Tabela 2 demonstra a grande predominância de atletas nascidos no primeiro semestre, apesar de haver diferenças entre os números absolutos, os resultados encontrados após a aplicação do teste binomial não apontaram diferenças significativas entre as proporções observadas. O fator "prova" também ficou dentro das expectativas, não havendo diferenças nas proporções.

Tabela 2. Freqüências apresentadas por categoria, prova realizada e nascidos em cada semestre do ano.

\begin{tabular}{|c|c|c|c|c|c|c|}
\hline & \multicolumn{2}{|c|}{ Estrada } & \multicolumn{2}{c|}{ Contra-relógio } & \\
\hline Categoria & $1^{\circ}$ Sem & $2^{\circ}$ Sem & $p$ & $1^{\circ}$ Sem & $2^{\circ}$ Sem & $\mathrm{P}$ \\
\hline $\begin{array}{c}\text { Junior } \\
\text { Feminino }\end{array}$ & 0,69 & 0,31 & 0,201 & 0,76 & 0,24 & 0,191 \\
\hline $\begin{array}{c}\text { Junior } \\
\text { Masculino }\end{array}$ & 0,71 & 0,29 & 0,188 & 0,52 & 0,48 & 0,657 \\
\hline $\begin{array}{c}\text { Juvenil } \\
\text { Fem. }\end{array}$ & 0,63 & 0,38 & 0,223 & 0,47 & 0,53 & 0,678 \\
\hline $\begin{array}{c}\text { Juvenil } \\
\text { Masc. }\end{array}$ & 0,81 & 0,19 & 0,176 & 0,71 & 0,29 & 0,188 \\
\hline $\begin{array}{c}\text { Infanto } \\
\text { Juv. Fem }\end{array}$ & 0,69 & 0,31 & 0,201 & 0,8 & 0,2 & 0,162 \\
\hline $\begin{array}{c}\text { Infanto } \\
\text { Juv. Mas }\end{array}$ & 0,7 & 0,3 & 0,183 & 0,85 & 0,15 & 0,156 \\
\hline Total & 0,71 & 0,29 & 0,188 & 0,68 & 0,32 & 0,221 \\
\hline
\end{tabular}

Os resultados encontrados nesse estudo com ciclistas confirmam outros resultados realizados em outros esportes com performance e maturação biológica, onde prevalece atletas nascidos no primeiro semestre na seleção de talentos.

A prova de contra-relógio, que apresenta características individuais, teve proporções iguais nos números absolutos nos atletas nascidos no primeiro e segundo semestre, nas categorias junior masculino e feminino e juvenil masculino e feminino. Esse resultado pode ter ocorrido devido a idade dos atletas (17- 18 anos e 1615 anos) onde os níveis hormonais já estão nivelados entre os adolescentes ${ }^{(1)}$, situação esta observada nas categorias principais e/ou profissionais, em que há uma tendência a se dissipar a idade cronológica, perdendo o referencial da linha de corte para a faixa etária ${ }^{(8,7,9)}$. $\mathrm{Na}$ categoria Infanto Juvenil masculino e feminino, houve predominância dos nascidos no primeiro semestre.

Esse desequilíbrio na seleção de talentos tem sido observado em vários esportes, como no tênis, no beisebol, no hóquei e mais recentemente no futebol por (3).

Na prova de estrada houve predomínio dos atletas nascidos no primeiro semestre em todas as categorias e em ambos os sexos. Nessa prova o trabalho da equipe toda influencia o resultado final, podendo ser este também um dos fatores determinantes no resultado geral. As categorias de iniciação ou de base apresentam diferenças advindas da idade relativa, sejam de ordem física ou cognitiva, podendo levar ao favorecimento do resultado final, inclusive por um produto da maior motivação(8). O autor ainda conclui que, a performance final e a motivação extrínseca favorecem à continuidade da prática esportiva, assim como a frustração da desigualdade do aspecto maturacional em relação aos seus companheiros pode causar o abandono precoce do esporte.

Tem-se utilizado muito a observação como forma de seleção e detecção de talentos na iniciação esportiva, favorecendo apenas a idade relativa em que se encontram alguns jovens favorecidos pelo aspecto maturacional, não levando em consideração a idade cronológica e maturação individual.

\section{CONCLUSÕES}

O resultado desse estudo com ciclistas concluiu que estáacorrendo exclusão precoce de talentos nainiciação, e sugere a criação de equipes multidisciplinares que pudessem avaliar de uma foram detalhada a condição individual e acompanhar a evolução desse atleta. Elementos como técnica, tática, física e psicológica que afetam diretamente a performance na competição devem ser levadas em conta no momento da seleção, pois corre-se o risco de dispensar talentos pela adoção inadequada de critérios de seleção. 
A "peneirada" deveria ser feita somente depois da igualdade da idade cronológica, categorias principais e/ou no profissional, pois sabemos que atletas de demoram anos para ser formados.

\section{REFERÊNCIAS BIBLIOGRÁFICAS}

1.Tourinho Filho, $\mathrm{H}$ e Tourinho, LSPR. Crianças, adolescentes e atividade física: aspectos maturacionais e funcionais. Rev Paul Educ Fís, 12(1), 71-84, 1998.

2. Baxter-Jones, Ad; Helms, P; Maffulli, N; BainesPreece, Jc E Preece, M. Growth and development of male gymnasts, swimmers, soccer and tennis players: a longitudinal study. Ann Hum Biology, 22(5), 381-94, 1995.

3. Mazzuco, MA; Pereira, JL e Silva, SG. O Efeito Relativo da Idade em Atletas de Futebol Profissional na Copa das Confederações/2005 e na Copa do Mundo da Alemanha/2006. Anais do XXIV Simpósio Internacional de Ciências do Esporte, CELAFISCS, São Paulo, 2006.

4.Beunen, GP; Malina, RM; Lefevre, J; Claessens, AL; Renson, $\mathrm{R}$ e Simons, J. Prediction of adult stature and noninvasive assessment of biological maturation. Med Sci Sports Exercise, 29(2), 225-230, 1997.

5. Matsudo, VKR e Matsudo, SMM. Avaliação e prescrição da atividade física na criança. Revista da Associação dos Professores de Educação Física de Londrina, 10(17), 46-55, 1995.
6. Paoli, PB; Silva CD; Soares AJG. Tendência atual da detecção, seleção e formação de talentos no futebol brasileiro. Rev Bras Futebol 2008 Jul-Dez; 01(2): 38-52 38.

7. Musch, J e Grondin, S. Unequal competition as an impediment to personal development: a review of the relative age effect in sport. Developmental Review, 21, 147-67, 2001.

8. Helsen, W.F; Winckel, J.V. e Williams, M. The relative age effect in youth soccer across Europe. Journal of Sports Sciences, 23 (6), 629-36, 2005.

9. Barnsley, R.H; Thompson, A.H. e Legault, P. Family planning: football style, the Relative Age Effect in football. International Review for Sociology of Sport, 27, 77-86, 1992.

\section{ENDEREÇO PARA CORRESPONDÊNCIA}

Endereço: Universidade Federal do Paraná - Departamento de Educação Física.

Curitiba - Paraná - Rua Urbano Lopes, 402 - CEP:80050-520

Telefone: (41) 3076-7685

E-mail: julianasta@gmail.com 